\title{
Incorporating social, behavioral and ethical components in medical curricula: the need and the challenges
}

\author{
Bilesha Perera $^{1}$, Vasantha Devasiri ${ }^{2}$, Susirith Mendis ${ }^{3}$, Gayani Punchihewa ${ }^{4}$ \\ ${ }^{1}$ Senior Lecturer in Community Medicine, ${ }^{2}$ Senior Lecturer in Paediatrics, ${ }^{3}$ Senior Professor in \\ Physiology, ${ }^{4}$ Lecturer in Psychiatry, Faculty of Medicine, University of Ruhuna, Galle.
}

Health care systems throughout the world are steadily changing to meet the diverse and emerging needs of the general public. eHealth (i.e. Health information and health care services on the internet), integration of allopathic and complementary medical services, growth of health insurance industry, law suits against health professionals and inclusion of emotional, spiritual and political well-being dimensions in defining 'health' reflect the new challenges and opportunities a newly appointed medical doctor has to appreciate and deal with [1-5]. In this context, the relevance and importance of social, behavioural and ethical underpinnings of patient care has increasingly being recognised $[5,6]$. Therefore, there is a compelling need to include these subject-areas in medical curricula $[4,7]$. Thus, an effective medical practitioner, who can successfully face the new demands in the new millennium, should have relevant knowledge, skills and right attitudes in social, behavioural, and ethical aspects of patient care and professional development.

Socio-ecological aspects of medical care or "Social Medicine" was almost a neglected area in medical curricula in early $20^{\text {th }}$ century, although in some European medical schools such as University of Zagreb in Croatia, Social Medicine had some recognition as early as 1931[8]. In the UK in early $20^{\text {th }}$ century, the medical curriculum was dominated by consultant physicians and surgeons of the teaching hospitals. Socioecological factors in prevention and treatment of diseases were not considered as important; as a result, patients with mental illnesses, sexually transmitted diseases and tuberculosis where social factors play a great role in aetiology and the course of the disease, did not have equal chance of getting admitted to teaching hospitals compared to patients with cardiac, respiratory or neurological diseases, or surgical problems [8]. The latter category of patients made doctors affluent. The income of doctors at that time depended on private practice as is the situation in Sri Lanka today. However, in 1930, a group of doctors by forming an association called 'The Socialist Medical Association', made the public and health authorities aware of the relationship between poverty and ill-health [9]. In 1943, the Interim Report of the Royal College of Physicians of London recommended that every medical school should establish a Department of Social and Preventive Medicine [10]. These developments influenced the UK government to establish the National Health Service in 1948. In addition, the establishment of the Society of Social Medicine in UK in the late 1950s accelerated the progress of the development of social medicine as a separate discipline. Today, medical humanities have been given a prominent place in the medical curricula in many medical schools throughout the world.

Since there are bio-psychosocial and ecological components in the etiology and course of disease $[5,7,11]$, patient care, disease prevention and health promotion all need progressive change in social structures leading to change in public policy. Thus, doctors should be skillful in fostering health by providing culturally sensitive and respectful patient-centered care. Approaching patients with a clear understanding of their bio-psycho-social and ecological variability, and thereby recognizing his or her own social biases in treating patients, a doctor would be able to provide much more effective care. Such a skillful doctor together with correct attitudes would be an asset to society as he or she would take proactive measures against various forms of prejudices and exploitations such as ethnic bias, racism and gender inequalities which adversely affect the health of the patients. Thus, by incorporating medical humanities into the 
curricula, medical schools would be able to produce doctors who are effective advocates for social change for the betterment of people. It is increasingly being recognised that social 'advocacy' is an additional duty of a 'good' doctor $[7,11]$.

In the early 1950s, research conducted by Sir Richard Doll, Sir Bradford Hill and other researchers in UK sparked the public awareness that certain lifestyle behaviours of people are linked with several conditions of ill-health prevailing in the community $[12,13]$. This momentum also resulted in extending epidemiological investigations from infectious diseases to non-communicable diseases. Today, non-communicable diseases are posing a major threat to the quality of the life of the people - mostly in the developed world but the threat is gradually spreading in the developing world as well [6]. Although major communicable diseases seen in the past such as smallpox and cholera have been eradicated, some other communicable diseases such as sexually transmitted diseases are on an upward trend at present. There is hardly a need for scientific evidence to understand the immediate causes of such highly prevalent communicable and noncommunicable conditions of ill-health seen in contemporary society. Unhealthy behavioral patterns such as sedentary life styles, substance use, poor dietary habits, and poor environments are the major factors associated with these conditions of ill-health; while poverty, social disorganisation, certain cultural beliefs and political factors are found to be some of the root causes [5-7].

Well-designed community health promotion strategies that curtail unhealthy behavioural patterns, promote reduction in social disparities and a holistic approach to health care where patients are considered as individuals and not as "cases" with signs and symptoms would eventually enhance the quality of life of the people. Further, by understanding socio-ecological and behavioral factors linked to health, relatively inexpensive curative and preventive interventions could be formulated; thus reducing the need for more expensive medical treatments.
Socio-political changes seen in the country indicate that there will be an excess of doctors for the state sector in Sri Lanka in the near future. The government will not be able to provide jobs in the state health sector for all newly passed out medical doctors. Therefore, there will be competition among medical graduates for the limited number of jobs available in both public and private sector medical institutes in Sri Lanka. A doctor who has a sound knowledge on behavioral risk factors of diseases and who can professionally advise a patient with regard to behavioral modifications the patients need to adapt to, and who fosters the correct attitude, will be in greater demand.

The Pond Report released by the Institute of Medical Ethics in UK in 1987 made some recommendations for the development of medical ethics teaching [14]. There has been an accelerated progress in teaching in medical ethics in medical schools since the release of the report. Today most medical schools around the world have medical ethics in their curriculum. Ethically sound medical practice would enhance the quality of the services provided by the doctor and would minimise the conflicts between patients, doctors, other staff and institutions.

At present, medical ethics has been included in medical school curricula as an "esoteric" subject. It is given peripheral importance and most medical students consider it a subject "outside" the core medical curriculum. Many researchers highlighted the need of expanding current teaching modules in medical ethics [14,15]. Medical students get exposed to real ethical dilemmas during their clinical years. During this period they experience certain ethical and professional conflicts that include covering up their lack of knowledge, skills and clinical experience from patients and failing to question unethical conduct of doctors when they perform procedures that carry considerable risks to patients without proper informed consent because of the fear of receiving poor grading $[15,16]$. There is a need to equip medical students with necessary knowledge, skills and attitudes to handle such incidents in a professional manner.

The need to inculcate right attitudes in medical undergraduates for the achievement of high standards in medical practice should also be given priority in the development of medical curricula. 
Recognition of patient's rights, ability to tolerate uncertainty, awareness of moral and ethical responsibilities, the need for high quality care, ability to adapt to change, eschewing dogmatism and arrogance are aspects that comes under the umbrella term of 'attitudes'. It is the right attitude of the doctor that would make a lasting impression on the patient.

It is observed that 'patient rights' has been receiving an increasing importance in the contemporary society [17]. In a global environment where United Nations declarations, charters and covenants such as the United Nations Declarations of Human Rights (UNDHR), International Covenants on Civil and Political Rights (ICCPR), International Covenant on Economic, Social and Cultural Rights (ICESCR) are gaining greater relevance and acceptance, the right to health is being integrated with patient rights. Medical students and doctors need to be made aware of these trends to ensure that they can work effectively in their professional role as health care providers.

Today many medical schools around the world feature a considerable social, behavioral and ethic teaching components in their curricular $[14,18]$. Some medical schools have incorporated behavioral and social science components in all four years of their medical education [18-20]. Moreover, some medical schools such as the Albert Einstein College of Medicine in USA, have recently introduced a three year residency program in Social Medicine for medical graduates [19]. As a former British colony, changes in British medical education have been reflected in our medical curricula as well, and at the end of $20^{\text {th }}$ century some of the medical faculties in Sri Lanka had taken steps to incorporate medical humanities, behavioral science and medical ethics into their curricula. The Faculty of Medicine, University of Ruhuna has done so from this year in the foundation course for new entrant medical students.

There are many challenges ahead of us in the process of incorporating and implementing the said courses in the medical curricular. It is heartening to find that the Bench Mark Statement on Medicine developed by the University Grants Commission has included some of these aspects [21]. Lack of qualified faculty and inadequate financial support may be the immediate barriers to implement these new programmes. Practical benefits of these subjects for clinical practice are not recognised by many in the medical field. These issues should be discussed among students, academics and teaching hospital consultants. Young academics should be encouraged to specialise or obtain postgraduate experience and training in these fields. Interdisciplinary teaching in these subjects should be encouraged and teaching of medical ethics and behavioural sciences should span the entire duration of medical studies for better results. The problem of evaluating and responding to reports of unprofessional or unethical behaviours of doctors and medical students is also highlighted by some researchers $[14,15]$. These critical issues should be taken into consideration when formulating and implementing medical ethics courses in medical schools. Developing a network among medical schools in Sri Lanka to identify teaching techniques, evaluation methods and research in these new fields would also help to improve the quality and effectiveness of the new subjects which will enhance the quality of medical education.

In conclusion, disease patterns in the community are changing so alarmingly that community health needs, both curative and preventive, are becoming more and more complex. Addressing these issues in an effective and timely manner is difficult. The quality and the usefulness of a medical practitioner in the near future will be determined by his or her ability to improve the patients' total health needs. An effective and quality doctor should have competencies in medical humanities, behavioural sciences and medical ethics as well to face these emerging challenges. University academics, hospital teaching staff and medical students must work together in this endeavour and reform medical education to produce quality and effective doctors who have capabilities of fulfilling future demands of society.

\section{References}

1. Wyatt JC, Sullivan F. eHealth and the future: promise or peril? British Medical Journal 2005; 331: 1391-3.

2. Larimore WL, Parker M, Crowther M. Should clinicians incorporate positive spirituality into their practices? 
What does the evidence say? Annals of Behavioral Medicine 2002; 24: 69-73.

3. Vickers A. Recent advances: Complementary medicine. British Medical Journal 2000; 321: 683-6.

4. General Medical Council. Tomorrow's doctors: recommendations on undergraduate medical education. London: GMC, 2002.

5. Viner R, Macfarlane A. Health promotion. British Medical Journal 2005; 330: 527-9.

6. World Health Organization. World Health Report. Geneva, Switzerland: WHO, 2004.

7. Institute of Medicine. Improving Medical Education: enhancing the behavioral and social science content of medical school curricula. Washington DC: National Academy of Sciences, 2004.

8. Pemberton J. Origins and early history of the society of social medicine May 2000 @ www.socsocmed.org.uk/history.htm

9. Stewart J. The battle for health: a political history of the Socialist Medical Association, 1930-51. London, Ashgate Publishing Ltd, 1999.

10. Royal College Physicians of London. Social and Preventive Medicine committee interim report, London, 1943.

11. Hafferty FW. Reconfiguring the sociology of medical education: emerging topics and pressing issues. In: Bird F, Conrad P, Fremont AM, eds. Handbook of Medical Sociology, $5^{\text {th }}$ ed. New York: Prentice Hall, 2000: 23856.
12. Doll, R, Hill, AB. The mortality of doctors in relation to their smoking habits. A preliminary report. British Medical Journal 1954; 48: 1451-5.

13. Hennekens $\mathrm{CH}$, Buring JE. Epidemiology in Medicine. Boston Little, Brown and Company, 1987: 10-13.

14. Mattick K, Bligh J. Teaching and assessing medical ethics: where are we now? Journal of Medical Ethics 2006; 32: 181-5.

15. Fryer-Edwards K, Wilkins MD, Baernstein A, Braddock $\mathrm{CH}$. Bringing ethics education to the clinical years: ward ethics sessions at the University of Washington. Academic Medicine 2006; 81: 626-31.

16. Christakis DA, Feudtner C. Ethics in a short white coat: the ethical dilemmas that medical students confront. Academic Medicine 1993; 68: 249-54.

17. Kaur SR, Herxheimer A. Recognizing patients rights: patchy progress. The Lancet 1994; 343: 132.

18. Russell A, Teijlingen E, Lambert H, Stacy R. Social and behavioral science education in UK medical schools: current practice and future directions. Medical Education 2004; 38: 409-13.

19. Albert Einstein College of Medicine. Residency program in Social Medicine. 17 October, 2003 @ www.aecom.yu.edu/family/rpsm.htm

20. Whittaker M, Dittrich LR. Humanities Education. Academic Medicine 2003; 78: 953-1075.

21. University Grants Commission. Subject Benchmark statement - Medicine. University Grant Commission, Colombo 2004. 